\title{
The Social Interaction Behavior in School Education-An Interpretation of Giddens' The Constitution of Society
}

\author{
Qingyuan Fang ${ }^{1}$ \\ School of Teacher Education, Ningbo University, Ningbo, Zhejiang 315211, China
}

\begin{abstract}
Since 1960s, with the rise of phenomenology and hermeneutics, structural sociology has been impacted to some extent. In Giddens' opinion, the structural sociology represented by Parsons greatly belittles the influence of individual's subjective initiative and cognitive ability on the society, and overemphasizes the dominant role of the society on the individual. However, interpretive sociology regards the material world such as society as the object world which is opposite to human existence and suspends the restriction of structure on individuals. According to Giddens, the problem of social theory is actually the problem of social order, that is, to explain how people transcend time and space and transcend the limitation of individual presence by means of social relations. Based on Giddens' social construction theory, this paper tries to explain the influence of communication behavior in school education on individual socialization of students.
\end{abstract}

Keywords: Giddens; The Composition of Society; Theory of Communicative Behavior; The School Education

Anthony Giddens is a British sociologist. He is famous for the theory of social structure and the ontology of contemporary society. His research involves sociology, psychology, politics, philosophy and other disciplines, and at the same time pushes the views of "modernity" and "globalization" to the center of sociological research. The Composition of Society: Outline of Structural Theory is a programmatic work of Giddens' sociological theory. Through sorting out the existing main sociological thoughts and schools, Giddens formed his own summary of the concept of sociology.

The interaction between individuals and society is influenced by a series of social practices of individuals. Through the individual consciousness of actors in social activities, actions are monitored reflectively. From the perspective of psychology and based on the theories of Freud and Mead, Giddens defined the actor as "the body subject existing as a whole". Moreover, Giddens further divided the behavior of actors into three levels: discourse consciousness, practical consciousness and unconsciousness. "Discourse consciousness means the ability to translate things into words" (Giddens, 1998, P114), which is the consciousness of individuals to make self-statements and expressions, as well as the ability of individuals to communicate socially. The practical consciousness refers to the "conscious" activities of the actor under the reflective supervision of himself. As Giddens points out, "reflective monitoring of action is a fusion of monitoring of this interactive scene, which is both typical and routine." (Giddens, 1998, P63) In the course of action, an actor has both discourse consciousness and practice consciousness, which determines that an actor consciously carries out reflective monitoring of his own behavior, and such reflective monitoring is combined with the scene of social interaction behavior of an actor.Individuals constantly present their discourse and actions in the social context, absorb the feedback of the results of this interaction, and grasp their own practical consciousness.

If we interpret the social structure from the perspective of individual behavior, we will inevitably ignore the constraints of society itself. In Giddens' opinion, the "structure" in structural theory is completely different from the "structure" in structural sociology. Instead, it is "understood as rules and resources, which are repeatedly reflected in the reproduction of social system" (Giddens, 1998, P270), which is the overall basis of structural theory. In Goffman's drama class theory, individual social activities are compared to a series of performance activities, and the concept of reception directly points to the interactive scene of individual performance activities. That is, the individual's social practice in daily life is based on the positioning of the scene. Giddens points out that because all interactions depend on situation-orientation, this means that the interaction itself takes place within the context.

\footnotetext{
1 About the author: Fang Qingyuan, 1997.8, female, native of Huangshan, Anhui; Master of Pedagogy Principle, Ningbo University; Research direction: Educational semiotics and educational sociology; Employer: School of Teacher Education, Ningbo University (315211); Telephone: 178-5582-3321, E-mail:1337063096@qq.com
} 
Daily life is extended and constructed in the routine space and time, forming the product of social practice activities -- system, and this process involves the rules and resources that are recycled and reused across the space-time relationship. "Examining the structural processes of social systems means exploring the ways in which systems such as these are produced repeatedly in interactions, based on the cognitive activities of actors in specific situations. In their actions, these actors make use of the rules and resources of a rich and varied context of action." (Giddens, 1998, P89) namely a kind of structural duality between the actor and the rule. From the perspective of structural duality, the structural characteristics of social system are not only the intermediary of social practice, but also the result of organization. This means that in another way structures impose more modest constraints on the actions of individuals.

Giddens also analyzes the power in school education. As a microcosm of society, there are also a lot of social interaction behaviors in schools. The students' school life is not only the classroom communication with teachers and the knowledge communication with texts, but also the individual communication with classmates and the surrounding environment. This series of communication practice constitutes the action flow in students' school life. Physical space and time, as well as all kinds of spiritual or material acquisition in school life, are structural resources in schools and universal means of moral education in schools. "In some ways, school discipline really goes back to the practice and control of time and space." (Giddens, 1998,228) school administrators divide school time so that students can enter structural time. Semester, school year and even the length of schooling have become a naming method for students' time. Through the one-to-one correspondence between individual time and institutional time, a cultural consensus on the structure of time is generated. In addition, the school institutional time cycle also includes the natural time cycle, which is divided into class time and rest time. Through the precise division of time structure, there is a connection between individual action and time -- the action logic of classroom time is obviously different from that of recess time; Morning reading time should read aloud, self-study time is not allowed to sound; You are not allowed out of school before school is over, etc.

Precise time division makes structured allocation of school activities and individual student actions and arranges them into different time dimensions. Students' daily homework, monthly exams, exams at the end of each semester, and various competitions and competitions at specific times of the year are all designed to routinize their daily activities using the configuration of time cycles. The examination and evaluation itself, through the cycle of time flow and routinization, constitutes the monitoring of students' ability and behavior results. "Although disciplinary control through monitoring is a powerful means of generating power, it still relies on the somewhat consistent deference of the 'subjects' who receive it." (Giddens, 1998, P229) From a long period to a short period, the concept of monitoring gradually penetrated into the practical consciousness of individual students, and became the social practice consciousness of students in their daily life in the continuous flow of action. The practical consciousness of each student in daily life becomes a formative element, which constitutes the collective self-reflective monitoring of students and the reflective monitoring of others.

In addition to the allocation of time and space, the allocation of authority resources promotes students' practical actions in a more active way. As mentioned above, the periodic evaluation system forms reflective monitoring in students' daily life practice. As a kind of school management means, honor evaluation promotes students' practical consciousness in two aspects through the distribution of honor discourse. First, on the level of writing, Michel Seto described writing in The Practice of Everyday Life as "a specific activity carried out in a wandering space -- a page of paper, whose purpose is to construct a text that has some power over the external world that originally separates it." (Seto, 2015, P222) Refers to the power of writing itself to construct a kind of text. Under the requirements of a certain production order, language fragments and symbolic materials are processed into a new expression system. The sense detached from the behavior of social reality returns to reality and applies to the outside world. The authoritatively honored writing, together with other texts written by students, has become the proof of individual identity and social practice. The meaning of students' life and self-reflection are constructed in the texts, and are also constructed under the supervision of others.

\section{References}

1 Anthony Giddens. The Constitution of Society: An Outline of structural Theory [M]. Trans. Li Kang and Li Meng. Beijing: New knowledge of Life and Reading, Sanlian Publishing House, 1998.

2 Michel de Seto. The Art of Practice [M]. Translated by Fang Linlin and Huang Chunliu. Nanjing: Nanjing University Press, 2015. 